\title{
LA REDUPLICACIÓN LÉXICA COMO MECANISMO DE EVALUACIÓN
}

\begin{abstract}
Resumen. La reduplicación es un mecanismo característico para varias lenguas del mundo. En español encontramos el fenómeno de la reduplicación léxica, esto es, la repetición de una unidad léxica dentro de un sintagma. Esta estructura suele ser asociada a diversos conceptos relacionados con la intensificación, cuantificación o superlación. En el presente trabajo se demuestra que la reduplicación léxica desempeña también un papel importante en la estructura argumentativa constituyendo uno de los recursos lingüísticos de la evaluación.
\end{abstract}

Palabras clave: reduplicación léxica, argumentación, evaluación, lingüística pragmática.

\section{Aspectos metodológicos}

La reduplicación léxica constituye uno de los mecanismos característicos para la comunicación oral en español. El hecho de repetir ciertas unidades propicia una serie de significados semánticos, en general relacionados con el aumento de la intensidad o con la focalización de cierta información. En el presente estudio demostramos que la reduplicación léxica desempeña también un papel importante a nivel pragmático: constituye un recurso de evaluación que forma parte de la estructura argumentativa del discurso.

\subsection{La reduplicación léxica}

El mecanismo de reduplicación forma parte de la estructura de distintas lenguas del mundo. Al examinar una serie de sistemas lingüísticos pertenecientes a varias familias, se puede observar que el hecho de

\footnotetext{
* Uniwersytet Łódzki.
} 
reduplicar ciertas unidades suele aportar numerosos significados que, aunque pueden ser de varia índole, se repiten en lenguas diferentes. Entre los trabajos más significativos que tratan de la reduplicación conviene señalar el artículo de Moravcsik (1978) que esboza la tipología de las reduplicaciones (totales o parciales) y sus posibles significados semánticos (como la pluralidad, el énfasis, la intensificación, la habitualidad o la continuidad). Otros investigadores llevaron a cabo unos estudios que profundizaban las cuestiones levantadas por Moravcsik: Marantz (1982) subraya el carácter fonológico de las estructuras reduplicadas, Ghomeshi, Jackendoff, Rosen y Russell (2004) proponen el concepto de la reduplicación contrastiva o Inkelas y Zoll (2005) introducen la teoría de Morphological Doubling Theory centrada no en los rasgos fonológicos del proceso, sino en las características morfológicas. Se puede notar, por lo tanto, que la reduplicación es un fenómeno estudiado desde el punto de vista de diversas perspectivas.

En las lenguas románicas encontramos el mecanismo de la reduplicación léxica, esto es, el hecho de repetir una misma unidad léxica dentro de un sintagma. Varios autores subrayan la existencia de este tipo de estructura en latín (véanse en Sorrento, 1950: 329-331; Rohlfs, 1968: 87; André, 1978). También en las lenguas románicas actuales, la reduplicación no se presenta desapercibida (sobre la reduplicación en francés, véase en Schapira, 1988, en catalán en Cabré, 2002: 910-920, en italiano en Rohlfs, 1968; Poggi Salani, 1971; Dressler y Merlini, 1994 o Wierzbicka, 1999).

La reduplicación léxica en español presenta varias peculiaridades tanto a nivel formal como semántico. En cuanto a su estructura sintáctica, Escandell (1991:72) distingue tres tipos: la reduplicación por yuxtaposición (guapo guapo), por coordinación (días y días) y por anteposición (entender, entiendo). Como indica Felíu (2011), cada una de estas construcciones necesita un estudio aparte, ya que presentan un comportamiento diverso. Por lo tanto, como objetivo del presente trabajo hemos escogido el primer tipo de reduplicaciones: las estructuras formadas mediante la yuxtaposición. Esta construcción puede abarcar diversas clases de palabras, esto es, tanto sustantivos (casa casa) como adjetivos (listo listo), verbos (trabajar trabajar), adverbios (rápido rápido) o incluso demostrativos (aquí aquî).

En cuanto al significado semántico, en los diferentes estudios encontramos varias propuestas de interpretación. Para Lamíquiz (1991), la reduplicación en español constituye un mecanismo de cuantificación. García-Page (1997), por su parte, enumera la reduplicación entre las estructuras de superlación. Escandell (1991) y Felíu (2011) reconocen en este tipo de construcciones la función de designación de prototipo. 
En varios trabajos, además, se menciona el papel que desempeña la reduplicación en el proceso de intensificación (véanse, por ejemplo, Roca y Suñer, 1998, o Albelda, 2007). En general, al hablar de la reduplicación en español se mencionan las categorías relacionadas con el aumento, intensidad, grado superior, énfasis o realce.

El objetivo de este estudio consiste en demostrar que la reduplicación léxica en español puede también desempeñar un papel importante al nivel pragmático. En la estructura argumentativa constituye un mecanismo lingüístico que propicia la evaluación. Como ya hemos señalado, la estructura que se somete al análisis es la reduplicación por yuxtaposición. Además, las unidades que forman parte de la construcción pertenecen a diversas clases de palabras (no nos limitamos a una categoría).

\subsection{La argumentación y la evaluación}

El presente trabajo se fundamenta sobre dos corrientes metodológicas estrechamente vinculadas entre sí: la teoría de argumentación y la teoría de evaluación. Ambas metodologías proporcionan una serie de propuestas que se aplican al fenómeno de la reduplicación léxica en español.

Entre los trabajos más significativos sobre la teoría de argumentación y sus vínculos con la lengua se encuentra la propuesta de Anscombre y Ducrot (1994). Según los autores, la argumentatividad es un rasgo característico para la mayoría de los enunciados. De este modo, el proceso de argumentar no se considera propio de unos textos específicos (como, por ejemplo, los jurídicos), sino que constituye un mecanismo presente en diversos tipos de creaciones lingüísticas. La mayoría de los enunciados, por lo tanto, sirve para convencer a alguien de algo, para influir al receptor. Este postulado fue desarrollado por Fuentes y Alcaide mediante un modelo detallado de la argumentación que la trata como una de las macroestructuras presentes, en diverso grado, en vario tipo de textos (véanse Fuentes y Alcaide, 2007; Fuentes, 2015). El segundo postulado de la teoría de la argumentación lingüística de Anscombre y Ducrot, desarrollado también por Fuentes y Alcaide, consiste en reconocer el valor argumentativo en determinadas expresiones lingüísticas. En otras palabras, existen unidades lingüísticas, a todo nivel del análisis, cuyo objetivo pragmático radica en apoyar el proceso de argumentar. La argumentación, por lo tanto, no es solo un recurso retórico, sino también una característica inherente de determinadas estructuras lingüísticas. 
El proceso de argumentar consiste en aportar una serie de argumentos para que el receptor llegue a una conclusión concreta o actúe de una manera determinada (Fuentes y Alcaide, 2007: 25-54). Los argumentos tienen que ajustarse al topos presente en la sociedad. Además, la argumentación se produce en un contexto dado (fuera de este contexto pueden surgir malentendimientos). El funcionamiento del proceso argumentativo lo presentamos mediante el siguiente enunciado:

\section{(1) Madre a hija: Llévate el paraguas para que no te mojes.}

La conclusión radica en el reconocimiento por parte de la hija de la imprescindibilidad de llevar el paraguas. El argumento aportado por la madre es que al no llevar el paraguas la hija puede mojarse. Para que el argumento sostenga la conclusión, hay que reconocer el topos: nadie quiere mojarse. Además, existe una situación en la que la argumentación parece razonable: cuando está lloviendo (si hace sol, el enunciado pierde el sentido argumentativo). Todo el proceso de argumentar está apoyado en una serie de recursos lingüísticos. Así que la madre utiliza una determinada entonación o recurre al imperativo para obtener el resultado previsto.

La evaluación, otro término clave para el presente análisis, a nuestro juicio, puede constituir un tipo de argumento. En otras palabras, mediante la evaluación el hablante introduce de modo directo un argumento a favor de cierta conclusión. En la lingüística existen varias definiciones de la evaluación (Hunston, 2011: 10-11). Se la suele explicar como una acción (algo que hace el hablante), un conjunto de expresiones que manifiestan significado evaluativo, una serie de significados (que pueden ser expresados mediante diferentes recursos), o bien una función del texto. Como indica Hunston, lo que une a estas posturas es el hecho de que la evaluación tiene carácter subjetivo e intersubjetivo: por una parte, expresa unos significados subjetivos, por otra, está dirigida al interlocutor. En el ámbito de la lingüística española podemos encontrar diferentes trabajos que vinculan la expresión de evaluación con determinados recursos lingüísticos. Haverkate (1995), por ejemplo, relaciona la elección de modo verbal con la expresión de la evaluación. Albelda (2007: 146-155), por su parte, incluye la evaluación como uno de los parámetros a la hora de analizar la estrategia de intensificación en español.

En el presente trabajo se recurre al concepto de evaluación como mecanismo argumentativo que radica en expresar una opinión o un juicio acerca de algo. Consideramos la evaluación como una estrategia de argumentación: al demostrar una opinión el hablante de modo directo 
indica cuál es la conclusión a la que espera que llegue el receptor. La evaluación presenta, por lo tanto, dos caras: por una parte, desempeña el papel subjetivo (manifiesta el punto de vista del hablante) y por otra, tiene carácter intersubjetivo (porque el hecho de presentar un juicio encamina al receptor hacia una conclusión concreta). Además, advertimos que entre los mecanismos lingüísticos que expresan contenidos evaluativos se encuentra la reduplicación léxica. De este modo, el presente análisis se estructura de la manera siguiente:

reduplicación léxica $\rightarrow$ evaluación $\rightarrow$ estrategia argumentativa

\section{El análisis}

El presente análisis está basado en dos corpus: la parte oral del corpus CREA (del español peninsular) y el corpus CORLEC que constituye un conjunto de transcripciones del registro oral. Se suele asociar el fenómeno de la reduplicación con el español hablado por lo que los textos orales nos parecen un material más adecuado para presentar ejemplos de este mecanismo. Como resultado de nuestro análisis hemos reconocidos dos casos: el primer caso son las reduplicaciones que en sí constituyen argumentos (evaluaciones), mientras que el segundo está compuesto por reduplicaciones cuya función tiene carácter de refuerzo argumentativo. En adelante, se explica el funcionamiento de estos dos tipos de estructuras.

\subsection{La reduplicación como argumento}

En el repertorio léxico de cada lengua existen unidades que ya en sí poseen carácter evaluativo y otros cuyo significado positivo o negativo depende del contexto y de la intención del hablante. Si comparamos dos adjetivos, feo y alto, podemos observar esta diferencia: feo suele indicar connotaciones negativas (raramente al decir feo se piensa en una calidad positiva), mientras que la interpretación del adjetivo alto depende de varios factores (en general, es una característica objetiva que luego puede ser interpretada como positiva o negativa dependiendo del punto de vista asumido por el hablante). En el primer grupo se encuentran las unidades léxicas cuyo significado puede ser difícilmente calificado 
como positivo o negativo: es la reduplicación y el contexto que les dotan de una evaluación concreta.

Como indica Wierzbicka (1999: 280), la reduplicación puede hacer hincapié en la veracidad de lo dicho. En otras palabras, al decir café café el hablante se refiere a un 'café de verdad' y no un 'café cualquiera'. El hecho de ser el representante prototípico de una categoría puede ser evaluado de modo positivo o negativo, según el contexto. De este modo, la reduplicación puede obtener dos interpretaciones:

$[X X]:$ ' $X$ de verdad'

- es positivo,

- es negativo.

Veamos un par de ejemplos:

(2) $\quad \mathrm{Y}$ ¿tienes preferencia por algún tipo de pintura concreta? Sí. Aunque sea muy antigua mi posición, pero no me gusta la pintura abstracta, me gusta la pintura pintura, o sea, en el sentido de que prefiero, o sea, de que sea figurativa, sea, exclusivamente figurativa.

SE-14. Mujer de 60. Profesora de instituto (España) CREA

En este fragmento, la reduplicación pintura pintura equivale a 'pintura de verdad'. El hablante evalúa el hecho de ser una pintura verdadera como algo positivo: es lo que ella prefiere. Además, el hecho de evaluar positivamente la pintura de verdad constituye un argumento a favor de la conclusión de que la pintura de verdad (que para ella es la figurativa) es mejor que la abstracta.

(3) H1: Y alumbra como una de cien. Imagínatelo en [ininteligible], no sé, lo que pasa es que es otro tipo de luz, es igual que entre la... la flo[palabra cortada], la mejor luz que hay es la florescente, la blanca, blanca. Es la mejor luz que hay, eso no hay... porque aquí hay ¿ves? esta es más blanca. Esta es...

H2: Sí, florescente.

CORLEC

El adjetivo blanco en sí no posee características positivas o negativas: es una cualidad que puede ser evaluada de una u otra manera dependiendo de la situación. En el ejemplo (3) el hablante quiere convencer a su interlocutor de que la mejor luz que hay es la florescente. Uno de los argumentos radica en afirmar que esta luz es blanca blanca, esto es, 'blanca de verdad'. El hecho de ser verdaderamente blanco constituye un argumento a favor de su tesis: en este caso, se evalúa la característica de ser blanco como positiva.

H1: ...tan así, tan...

$\mathrm{H} 2$ : Que es calladito, calladito.

H1: Claro. 
H2: Y él no... se atreve a decir si no lo entiende o si nada.

CORLEC

El adjetivo calladito puede tener dos interpretaciones: una positiva (cuando una persona no es demasiado ruidosa) y otra negativa (cuando una persona no habla cuando debería hacerlo). En (4) la expresión calladito viene utilizada con matiz negativo: un alumno es demasiado tímido y no se atreve a decir nada. Al reduplicar esta unidad, el participante $\mathrm{H} 2$ evalúa negativamente el comportamiento del alumno: es 'calladito de verdad' (y no un poco más tranquilo que el resto de los alumnos).

\subsection{La reduplicación como refuerzo del argumento}

El segundo grupo viene representado por las reduplicaciones que se forman a partir de las unidades de significado caracterizado por unas connotaciones concretas. Estas unidades en sí poseen carácter evaluativo: su significado semántico propicia una interpretación positiva o negativa. La función de la reduplicación funciona como refuerzo argumentativo: al reduplicar una unidad se hace hincapié en su evaluación positiva o negativa y así se refuerza el argumento que incita cierta conclusión. Tal es el caso en los tres ejemplos siguientes:

y es un pueblo que me encanta porque es ideal, tiene un o sea, por no tener no tiene ni agua. Para verano. No tiene ni agua en las casas, pero es ideal ideal, tiene unos paisajes preciosos, es yo lo encuentro grandioso, es es muy bonito, tiene unos unos alrededore

MA-3. Mujer de 25 años. Ha estudiado la carrera de piano y canto (España) CREA

El significado semántico de ideal ya en sí propicia una interpretación positiva (salvo casos del empleo como recurso irónico). De este modo, la reduplicación no constituye un nuevo argumento, más bien refuerza la evaluación positiva de esta expresión. Al reduplicar se intensifica la evaluación positiva y así aumenta la fuerza argumentativa de este fragmento. Una situación parecida ocurre en en el ejemplo (6), pero esta vez estamos ante el refuerzo de la interpretación negativa:

(6) o sabía dónde estaban, pues me fui a por ellos, los saqué y los metí en el talego, cuando llegué a mi casa estaba todo cagado, todo lleno de mierda de pájaro, porque además esos pájaros cagan mucho. cuando llegué a mi casa veo a mi madre con los pájaros, "todos los patio todos los pájaros por el patio, los gatos por un sitio, los los pájaros corriendo por un sitio, por el otro". Bueno, demasiado demasiado. Era otra cosa.

Conversación 15, Universidad de Alcalá de Henares (España) CREA 


\section{A modo de conclusión}

En el presente artículo hemos intentado demostrar que la reduplicación léxica en español, aparte de caracterizarse por unos valores semánticos específicos, desempeña un papel importante en el proceso de argumentación. Mediante la reduplicación los hablantes pueden evaluar positivamente o negativamente un hecho, una persona o un objeto y así dirigir a su interlocutor hacia una conclusión concreta. De este modo, se afirma que el mecanismo de repetir una unidad dentro de un sintagma puede también obtener una interpretación a nivel pragmático.

\section{Bibliografía}

ALBELDA MARCO, M. (2007). La intensificación como categoría pragmática: revisión y propuesta. Una aplicación al español coloquial. Frankfurt am Main: Peter Lang. ANDRÉ, J. (1978). Les mots à redoublement en latin. Paris: Klincksieck.

ANSCOMBRE, J. y DUCROT, O. (1994). La argumentación en la lengua. Madrid: Gredos (trad. J. SEVILLA y M. TORDESILLAS).

CABRÉ MONNÉ, T. (2002). «Altres sistemes de formació de mots», en J. SOLÀ et al. (ed.), Gramàtica del català contemporani, vol. 1. Barcelona: Empúries, 889932.

CORLEC - CORPUS ORAL DE REFERENCIA DEL ESPAÑOL CONTEMPORÁNEO [en línea] <http://www.lllf.uam.es/ESP/Info\%20Corlec.html>, fecha de consulta: 4 de mayo de 2018.

CREA - Corpus de referencia del español actual. REAL ACADEMIA ESPAÑOLA: Banco de datos [en línea] <http://www.rae.es $>$, fecha de consulta: 4 de mayo de 2018.

DRESSLER, W. U. y MERLINI BARBARESI, L. (1994). Morphopragmatics. Diminutives and Intensifiers in Italian, German, and Other Languages. Berlin / New York: Mouton de Gruyter.

ESCANDELL VIDAL, M. (1991). «Sobre las reduplicaciones léxicas», LEA: Lingǘstica española actual, 13/1, 71-86.

FELIU ARQUIOLA, E. (2011). «Las reduplicaciones léxicas nominales en español actual», Verba, 38, 95-126.

FUENTES RODRÍGUEZ, C. (2015). Lingüística pragmática y análisis del discurso. Madrid: Arco Libros.

FUENTES RODRÍGUEZ, C. y ALCAIDE LARA, E. (2007). La argumentación lingüística y sus medios de expresión. Madrid: Arco Libros.

GARCÍA-PAGE, M. (1997). «Formas de superlación en español: la repetición», Verba, 24, 133-157. 
GHOMESHI, J., JACKENDOFF, R., ROSEN, N. y RUSSELL, K. (2004). «Contrastive focus reduplication in English (the salad-salad paper)», Natural Language \& Linguistic Theory, 22, 307-357.

HAVERKATE, H. (1995). «Spanish mood and the expression of cognitive and evaluative meaning», Verba, 22, 11-29.

HUNSTON, S. (2011). Corpus Approaches to Evaluation. Phraseology and Evaluative Language. New York / London: Routledge.

INKELAS, S. y ZOLL, C. (2005). Reduplication. Doubling in Morphology. Cambridge: Cambridge University Press.

LAMÍQUIZ, V. (1991). La cuantificación lingüística y los cuantificadores. Madrid: Universidad Nacional de Educación a Distancia.

MARANTZ, A. (1982). «Re Reduplication», Linguistic Inquiry, 13, 435-482.

MORAVCSIK, E. (1978). «Reduplicative Constructions», en J. H. GREENBERG (ed.), Universals of Human Language, vol. 3. Stanford: Stanford University Press, 297-334.

POGGI SALANI, T. (1971). «Il tipo caffé caffé», Lingua Nostra, 32, 67-74.

ROCA, F. y SUÑER, A. (1997-1998). «Reduplicación y tipos de cuantificación en español», Estudi general: Revista de la Facultat de Lletres de la Universitat de Girona, 17-18, 37-67.

ROHLFS, G. (1968). Grammatica storica della lingua italiana e dei suoi dialetti. Morfologia. Torino: Einaudi (trad. T. FRANCESCHI).

SCHAPIRA, C. (1988). «Le redoublement expressif dans la création lexicale», Cahiers de lexicologie, 52, 51-63.

SORRENTO, L. (1950). Sintassi romanza. Varese-Milano: Istituto Editoriale Cisalpino.

WIERZBICKA, A. (1999). «Włoska reduplikacja. Pragmatyka międzykulturowa i semantyka illokucyjna», en A. WIERZBICKA y J. BARTMIŃSKI (eds.), Jezyk - umyst - kultura. Warszawa: PWN, 270-299. 